\title{
Studies on the Asian sawflies of Formosempria Takeuchi (Hymenoptera, Tenthredinidae), with notes on the suitability of $F$. varipes Takeuchi as a biological control agent for skunk vine, Paederia foetida L. (Rubiaceae) in Florida
}

\author{
David R. Smith', Paul D. Pratt², Jeff Makinson ${ }^{3}$
}

I Systematic Entomology Laboratory, Agricultural Research Service, U. S. Department of Agriculture, clo National Museum of Natural History, Smithsonian Institution, P.O. Box 37012, MRC 168, Washington, D.C. 20013-7012 2 Invasive Plant Research Laboratory, Agricultural Research Service, U. S. Department of Agriculture. Ft. Lauderdale, FL 333143 USDA, ARS, Australian Biological Control Laboratory, CSIRO Ecosystem Sciences, GPO Box 2583, Brisbane, Queensland, Australia 4001

Corresponding author: David R. Smith (sawlly2@aol.com)

Academic editor: S. Schmidt | Received 13 June 2014 | Accepted 25 August 2014 | Published 26 September 2014

http://zoobank.org/F44C9C52-572D-4436-8DOB-A6F47A0D2FE9

Citation: Smith DR, Pratt PD, Makinson J (2014) Studies on the Asian sawflies of Formosempria Takeuchi (Hymenoptera, Tenthredinidae), with notes on the suitability of $F$. varipes Takeuchi as a biological control agent for skunk vine, Paederia foetida L. (Rubiaceae) in Florida. Journal of Hymenoptera Research 39: 1-15. doi: 10.3897/JHR.39.8096

\begin{abstract}
Formosempria Takeuchi, 1929, is distributed in southeastern Asia from Taiwan and China to Vietnam, Myanmar, and possibly northern India. Three species are included: F crassicornis Wei \& Nie, 2002, F. shanensis Malaise, 1961, and F. varipes Takeuchi, 1929 (= F. annamensis Malaise, 1961, syn. n.; = F. metallica Wei, 2003, syn. n.). Formosempria varipes was reared from larvae feeding on Paederia foetida L. (Rubiaceae) in Hong Kong and was a potential biological agent for the invasive P. foetida in Florida. Larval feeding tests indicate more than one species of Paederia are suitable hosts for F. varipes and further study for use as a biological control agent in Florida is unwarranted. Descriptions and illustration of the species are given, and life history notes on $F$. varipes are presented.
\end{abstract}

\section{Keywords}

Symphyta, biological control, skunk vine

Copyright David R. Smith et al. This is an open access article distributed under the terms of the Creative Commons Attribution License (CC BY 4.0), which permits unrestricted use, distribution, and reproduction in any medium, provided the original author and source are credited. 


\section{Introduction}

Interest in the small and little-known genus Formosempria Takeuchi was prompted by discovery of larvae of a species in Hong Kong feeding on skunk vine, Paederia foetida L. (Rubiaceae), a target for a biological control program in Florida (Pemberton and Pratt 2002). Adults reared from these larvae were identified as a species of Formosempria, an Asian genus in the subfamily Allantinae. Taeger et al. (2010) listed five described species in this genus, distributed from Taiwan and western and southern mainland China to Vietnam, Myanmar, and possibly northeastern India. Very few specimens of Formosempria were previously available for study, most of which are types of the described species, but additional specimens from Taiwan and those reared from Hong Kong have become available. The identity of the Hong Kong species, as outlined here, is Formosempria varipes Takeuchi, 1929, which was described from Taiwan.

Formosempria was based on a single species, F. varipes, described from a single specimen (Takeuchi 1929). Malaise (1961) added two species, F. annamensis from Vietnam and $F$. shanensis from Myanmar, and gave a key to the three species. Wei and Nie (2002) and Wei (in Wei and Nie 2003) added F. crassicornis and F. metallica from China. Saini and Deep (1994) and Saini (2006) reported F. shanensis Malaise, the species described from Myanmar, from India, but this is questionable. The genus probably does not occur in India. Haris (2012) recorded F. crassicornis from Vietnam. Critical to the study of Formosempria is the identity of the type species of the genus, F. varipes Takeuchi. Unfortunately, the type could not be located. However, among some specimens from Taiwan we found a series identical to Takeuchi's description of $F$. varipes. We use these specimens to characterize Formosempria and the included species.

Discovery of $F$. varipes feeding on Paederia in Hong Kong initiated studies on the species as a possible biological control agent for $P$. foetida in Florida. However, host preference studies showed that several species of Paederia may serve as host plants, thus making it unsuitable for release as a biological control agent of $P$. foetida in Florida.

\section{Material and methods}

Figures 1-15 were obtained using an EntoVision Imaging Suite that included a firewire JVC KY-75 3CCD digital camera mounted to a Leica M16 zoom lens via a Leica z-step microscope stand. Multiple focal planes were merged using Cartograph 5.6.0 (Microvision Instruments, France) software. Figures 16-18 were prepared by PDP.

Acronyms used are: CSCS (Collection of Central South University of Forestry and Technology, Changsha, Hunan, China); FSCA (Florida State Collection of Arthropods, Gainesville, FL, USA); IPRL (Invasive Plant Research Laboratory, Agricultural Research Service, U. S. Department of Agriculture. Ft. Lauderdale, FL, USA); NHR (Naturhistoriska Riksmuseet, Stockholm, Sweden); UOP (University of Osaka Prefecture, Sakai, Japan); SDEI (Senckenberg Deutsches Entomologisches Institut, 
Müncheberg, Germany); USNM (National Museum of Natural History, Smithsonian Institution, Washington, D.C., USA).

Recent surveys by JM resulted in the discovery of numerous $F$. varipes larvae feeding on the foliage of P. foetida in the Sham Tseng area (N 22.373, E114.064), Hong Kong. Taxonomic and biological assessments were based on F.varipes individuals that were shipped from Hong Kong in March 2013 and April 2014 to the quarantine facility at IPRL, under permit \#P526P-12-04814. In an effort to establish a laboratory colony of $F$. varipes, 25 males and 25 females from the 2013 shipment were added to each of three screen cages $(33 \times 33 \times 61 \mathrm{~cm})$ within the quarantine glasshouse $\left(28^{\circ} \mathrm{C}\right.$ $( \pm 5), 85 \%( \pm 10)$ relative humidity). Each cage contained a potted $P$. foetida plant as well as several cotton balls hydrated with dionized water, which were positioned on the top surface of each cage. Observations of these adults, the resulting eggs, and larvae were recorded.

A subset of adults arising from the 2014 shipment were incorporated into nochoice host range tests, which were designed to quantify the propensity of $F$. varipes to oviposit and feed on select Paederia species. Among the Paederia, only Paederia ciliata (Bartl. ex DC) Standley is native to North America and has a geographic range limited to Mexico (Puff 1991). The release of $F$. varipes as a biological control agent of $P$. foetida in Florida may pose significant risk to the Mexican endemic if female sawflies recognize $P$. ciliata as an ovipositional host and larvae complete development when feeding exclusively on the plant. To test these host use patterns, five replicate $P$. ciliata or $P$. foetida potted plants were placed in individual screen cages $(33 \times 33 \times 61 \mathrm{~cm})$ within a quarantine glasshouse as described above. Plants were pruned to ensure a uniform height and biomass among individuals. Five malefemale pairs, each less than 24 hours old, were randomly assigned to each cage and held with the test plant until death. Each plant was reviewed for oviposition incidence 7 days following adult inoculation and larval densities per plant were noted 21 days after adult release.

Additionally, no-choice larval tests were conducted to determine if $P$. ciliata is a developmental host. Other Paederia species were also included to provide insights into the generic specificity of the herbivore: Paederia bojeriana (Rich.) Drake, P. cruddasiana Prain, $P$. pilifera Hook., and the target weed $P$. foetida. Tests were conducted in a single controlled environmental chamber set at $25{ }^{\circ} \mathrm{C}, 75 \%$ relative humidity and 14:10 light:dark. Neonate larvae ( $<24$ hrs old) were collected from the laboratory colony and five individuals were transferred onto a slightly moistened filter paper within individual $90 \times 15 \mathrm{~mm}$ petri dishes. Five replicate petri dishes with the accompanying larvae were randomly assigned one of five replicated plants for each of the five host plant treatments. Leaves were excised from assigned test plant replicates and placed within the petri dish, which was sealed with parafilm and maintained at internal conditions of $25^{\circ} \mathrm{C}$ and $90 \%$ relative humidity. A mixture of soft, newly developing and mature, fully expanded leaves in excess of the herbibore's daily consumption were added to each petri dish every 24 hours. Survivorship was monitored daily and larval development time to the prepupal stage was noted. The influence of host plant species 
on oviposition, larval survival, and development rates were compared with ANOVA followed by Tukeys HSD post hoc analysis (PROC GLM; SAS 1999). Data are presented as means ( \pm standard error).

\section{Results}

\section{Systematics}

\section{Formosempria Takeuchi}

Formosempria Takeuchi 1929: 85.Type species: Formosempria varipes Takeuchi, original designation; Malaise 1961: 247 (diagnosis; key to 3 species); Malaise 1963: 159 (in world key); Togashi 1990: 184 (one species, Taiwan); Abe and Smith 1991: 34 (genus listed); Chou and Naito 1991: 89 (one species, Taiwan); Saini and Deep 1994: 48 (one species, India); Wei and Nie 1998: 28 (placed in Blennocampidae, Belesesinae, Atelozini); Wei 2001: 678 (one species, Zhejiang, China); Lacourt 2003: 506 (in Allantinae, Atelozini); Wei et al. 2006: 527 (three species listed from China); Saini et al. 2006: 579 (one species, India); Xiao 2006: 192 (one species listed from China); Taeger et al. 2010: 282 (world catalog, five species listed); Haris 2012: 138 (one species, Vietnam).

Description. Antenna (Figs 3, 10) hairy, stout and slightly thickened medially; scape longer than broad; pedicel as long as broad, antennomere 3 longer than 4; apical 3 antennomeres each with ventral sensory area. Malar space linear; clypeus (Figs 4, 8) truncate or bluntly protruding anteriorly; each mandible with large subapical tooth; inner margins of eyes slightly converging below (Figs 4, 8); genal carina absent; head from above strongly narrowing behind eyes (Figs 5, 9). Epicnemium absent. Forewing (Fig. 2) with 4 cubital cells; hind wing (Fig. 2) without cells Rs and M, anal cell with short petiole. Inner fore tibial spur appearing simple but with very slight preapical projection. Tarsal claws (Fig. 11) with long inner tooth, nearly as long as outer tooth and lateral to outer tooth, with basal lobe. Pulvilli small on hind tarsomeres 3 and 4 . Head and body usually with slight metallic luster.

Remarks. Species of Formosempria are superficially similar to species of Empria, being similar in size and color and similar wing venation; thus, the reason for the name. Takeuchi (1929) mentioned that they are like Empria, but without a malar space. Formosempria will key to the same couplet as Hemibeleses in Malaise's 1963 key, but are separated from Hemibeleses which has the pedicel as long or longer than the scape and the 3-toothed hind claws in the male. Males of Formosempria were not known at that time, but the hind claw is similar to the fore- and midclaws, not 3-toothed as in Hemibeleses.

Based on this study, two species of Formosempria are recognized, F. varipes from Taiwan, southeastern China, and Vietnam, and F. shanensis from Myanmar. Formosem- 
pria crassicornis Wei and Nie is listed, but the type was not examined and its status cannot be determined. The record of Formosempria from India by Saini and Deep (1994) and Saini (2006) is questionable.

\section{Formosempria crassicornis Wei \& Nie}

Formosempria crassicornis Wei and Nie 2002: 837, 839, 846, 848, figs 10, 11 (female sheath, saw on p. 848); Wei et al. 2006: 527 (listed); Haris 2012: 138 (recorded from Vietnam).

Comments. This species was described from Hainan, China. The holotype, deposited in the Institute of Zoology, Chinese Academy of Sciences, Beijing, was not examined.

The figures by Wei and Nie (2002) of the female sheath and lancet do not differ from $F$. varipes, and $F$. crassicornis may be a synonym. Even though distinguishing characters for the species are not evident in the description and the species seems to fall within the range of $F$. varipes, it is kept valid until the type can be examined. Haris (2012) recorded a female from Vietnam ("N. Vietnam, Ninh Binh, Cue Phuong NP, near centre, c. 225 m, 20.xii.1999-19.ii.2000"), but gave no discussion. This specimen was not examined.

\section{Formosempria shanensis Malaise}

Figs $1-5$

Formosempria shanensis Malaise 1961: 249, fig. 8A,B,C (head front; antenna, sheath dorsal); Malaise 1963: figs 73, 131; Saini and Deep 1994: 48 (listed; first record from India); Saini 2006: 68, 152, figs 215-222 (India record; male described); Saini et al. 2006: 579 (listed).

Comments. Malaise described this species from five females from "Burmese Southern Shan States (Taunggyi at $1500 \mathrm{~m}$ )". The syntypes are in NHR and were examined. The lectotype, here designated, is a female labeled "S. Shan States, Burma, $1500 \mathrm{~m}$, Taunggyi, 1-VIII-22.IX.34 ["22.IX" crossed out], Malaise", "TYPUS" [red], "Formosempria shanensis n. sp., R. Malaise det 1958”, "NHRS-HEVA 000000834” with a lectotype label added. The other four females are paralectotypes with the same data but with the label "PARATYPUS" [in red]; three do not have dates crossed out and one has "1-VIII" crossed out.

The color and structure are very similar to $F$. varipes, but $F$. shanensis differs by its slightly larger size, the more truncate clypeus with more acute lateral corners (Fig. 4, more rounded laterally in $F$. varipes, Fig. 8), and longer antennae (Fig. 1), being more than half the length of the body (thorax and abdomen) and about $2.2 \times$ the head width. These differences seem significant to retain $F$. shanensis as a distinct species at present. 

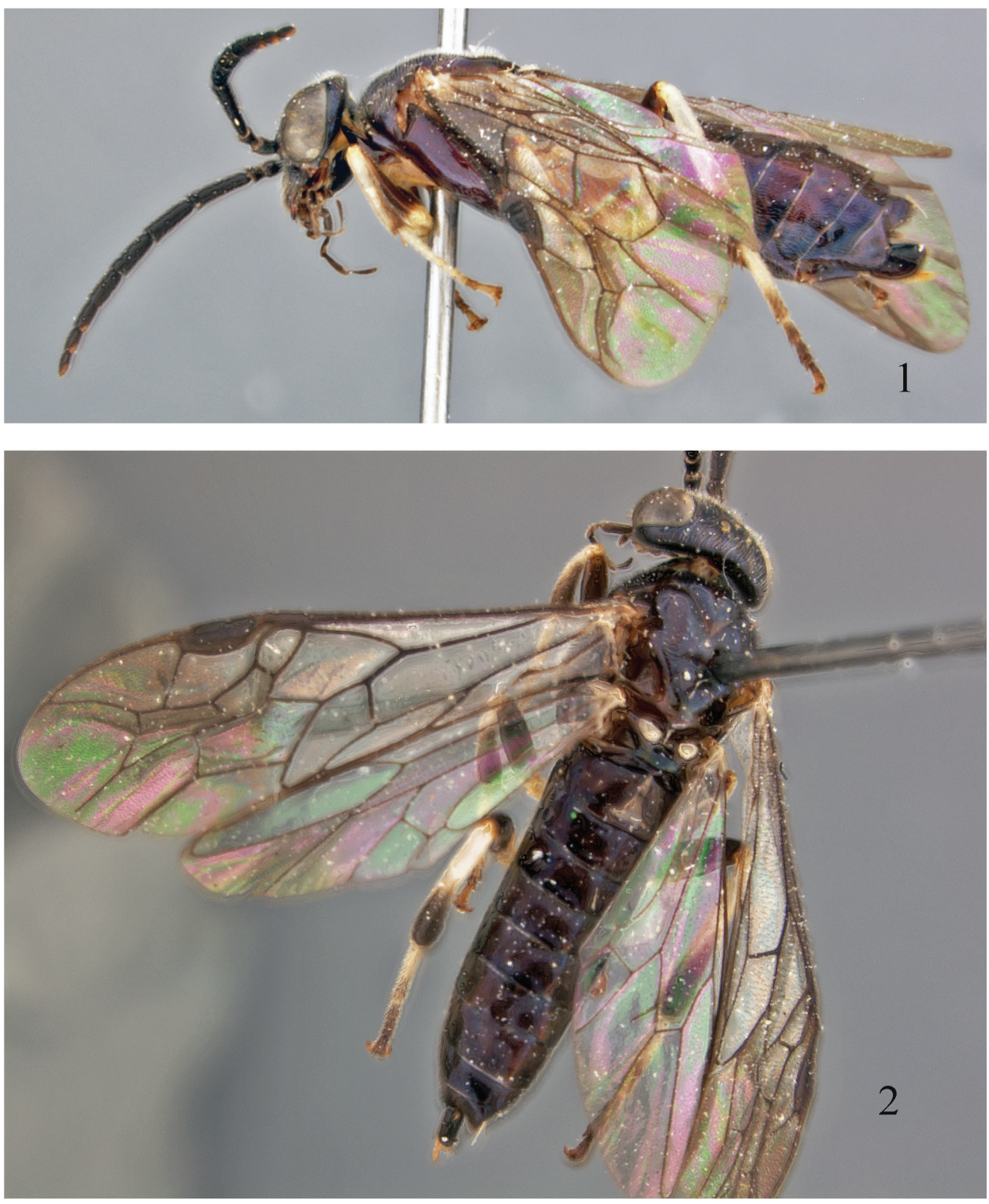

Figures I-2. Formosempria shanensis, lectotype. I Lateral 2 Dorsal.

Saini and Deep (1994) and Saini (2006) recorded this species from five males from India: "Himachal Pradesh, Dalhousie, Kalatop, 2850 m, 29.6-30.6.1986”. Saini (2006) mentioned these are the first known males of the genus, although Wei (in Wei and Nie 2003) described the male of F. metallica. Saini (2006) also included description of the female. These specimens have three-toothed hind claws and the genitalia figured are quite different from that of associated males of $F$. varipes. We have not seen 

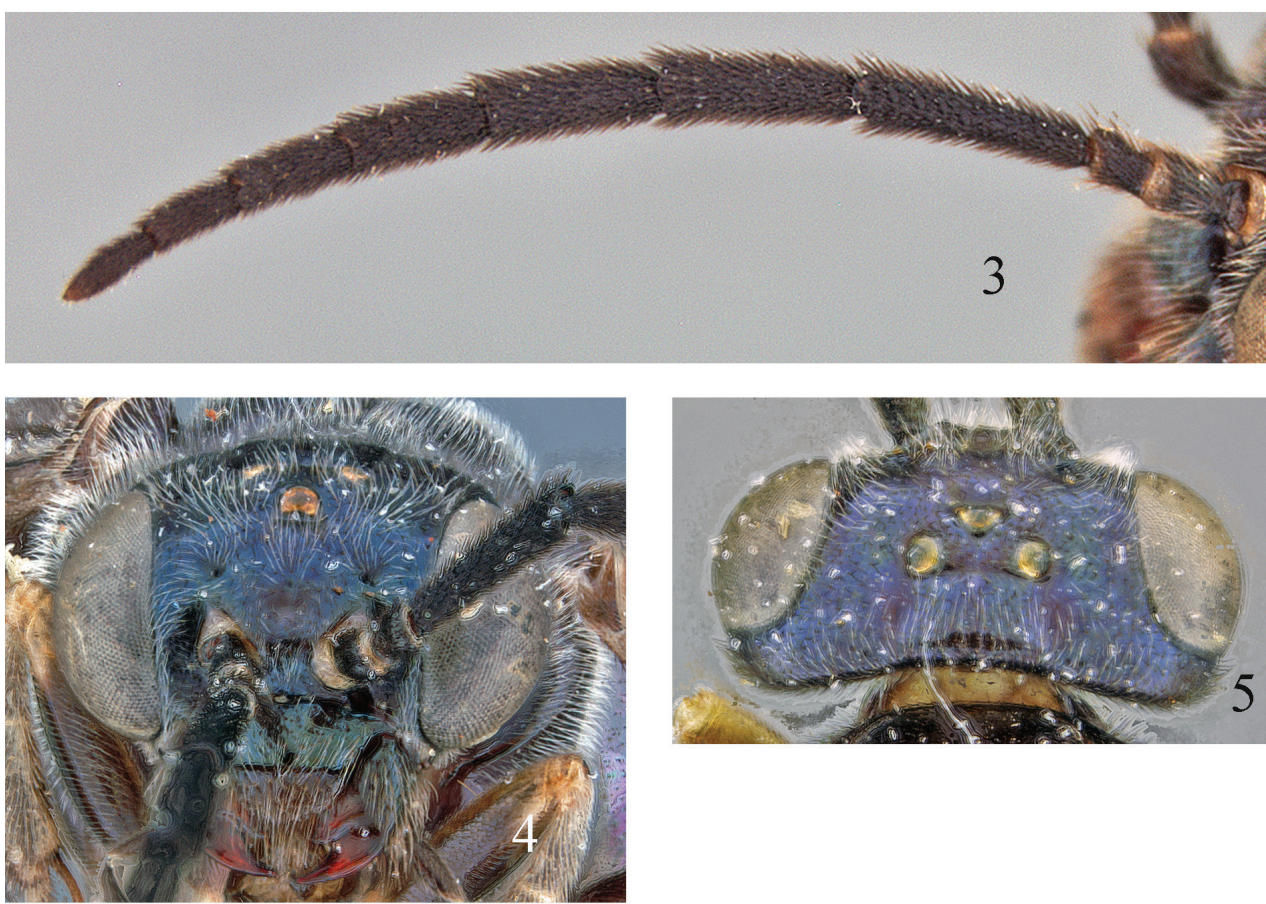

Figures 3-5. Formosempria shanensis, lectotype. 3 Antenna 4 Head, front 5 Head, dorsal.

specimens, but according to Saini's (2006) description, we question that these are $F$. shanensis or even a member of Formosempria. Thus, the India record for Formosempria is doubtful.

\section{Formosempria varipes Takeuchi}

Figs 6-18

Formosempria varipes Takeuchi, 1929: 85-86. Figure of wings; Malaise 1961: 249 (in key); Togashi 1990: 184, figs 46-50; Wei et al. 2006: 527 (listed).

Formosempria annamensis Malaise, 1961: 249. syn. n.

Formosempria metallica Wei, in Wei and Nie 2003: 136-137, 207, figures, male and female; Wei et al. 2006: 527 (listed). syn. n.

Description. Female: Length, 6.5-7 mm. Black, with slight metallic lustre, and following white: apices of coxae, trochanters, basal third of mid and hind femora, basal third to half of mid and hind tibiae, base of hind basitarsus, most of mid and fore basitarsi. Wings lightly, uniformly infuscated; veins and stigma black. Head and body with slight metallic luster, smooth, shiny, with short silvery hairs.

Antenna (Figs 6, 10) with scape longer than broad; pedicel about quadrate; antennomere 3 longer than 4, remaining antennomeres gradually decreasing; length less 

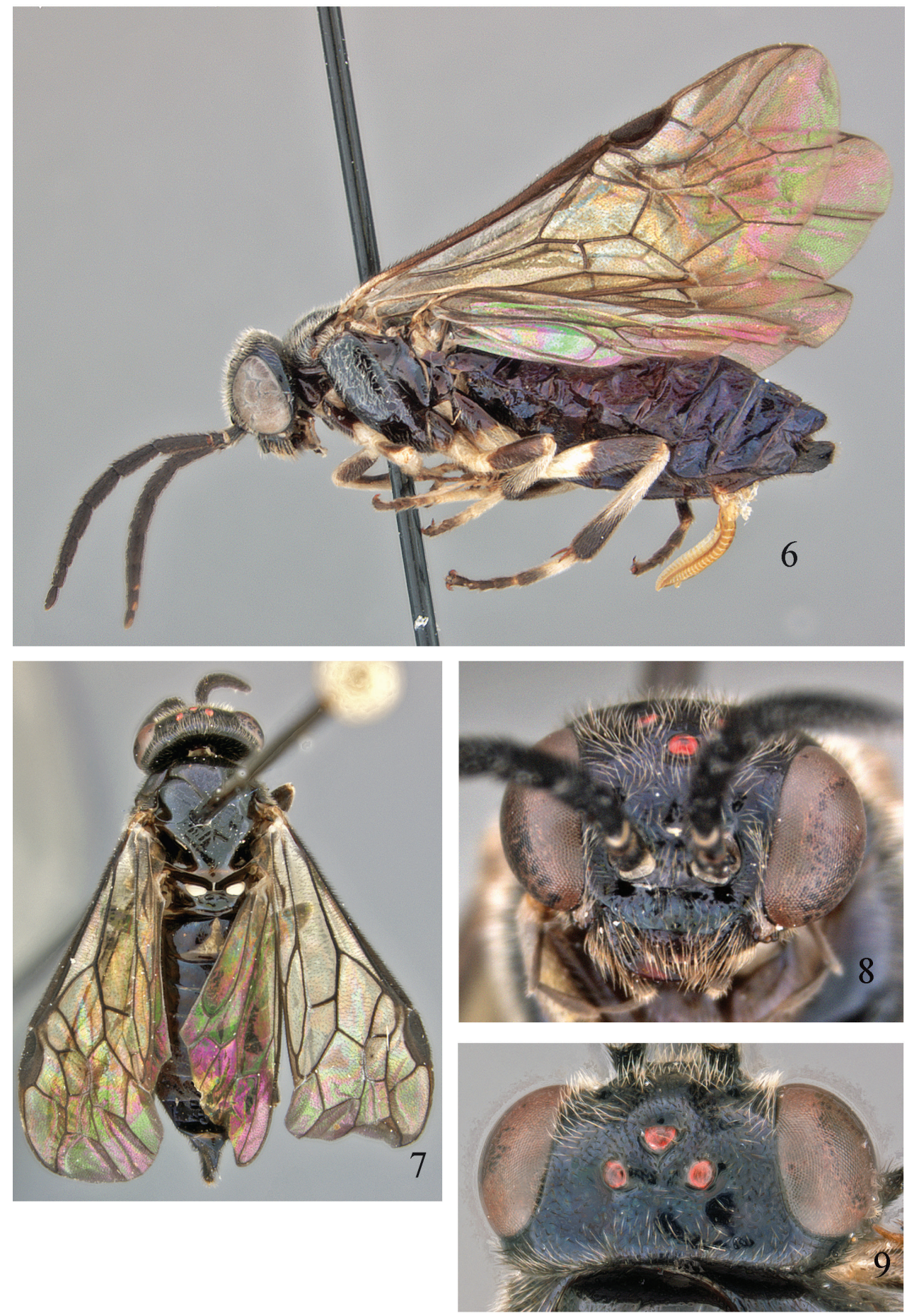

Figures 6-9. Formosempria varipes. 6 Lateral 7 Dorsal 8 Head, front 9 Head, dorsal. 
than half body length (thorax and abdomen) and about $1.7 \times$ head width. Clypeus truncate to slightly protruding anteriorly, with corners rounded (Fig. 8). Malar space linear. Hind basitarsus (Fig. 11) about equal to length of remaining tarsomeres combined. Sheath (Fig. 13) slender in dorsal view, in lateral view slightly truncate at apex, appearing slightly directed dorsally. Lancet (Fig. 12) with serrulae low, pointed at apices, each with about 6 fine anterior and posterior subbasal teeth.

Male: Length, $6.5 \mathrm{~mm}$. Similar in color and structure to female. Genitalia in Figs 14, 15.

Neonates (Fig. 17): Similar to late feeding stage.

Last feeding stage (Fig. 18): Length, about $12 \mathrm{~mm}$. Head black with postclypeus, preclypeus, area between antacorium and clypeus and mandible, mandible except apex and mouthparts except apices of palpi whitish; labrum brownish. Thorax and abdomen entirely pale with whitish bloom. Head with long scattered setae, longer than preclypeus; preclypeus with 2 setae on each side; labrum with 3 setae on each side; right mandible with 3 small ventral teeth and 2 acute and one broad dorsal teeth; left mandible with 2 acute ventral teeth and 4 acute dorsal teeth and with inner ridge extending inward from outer dorsal tooth. Thorax with scattered long setae. Abdominal segments each with 6 dorsal annulets; 2-3 setae on each side of annulets 2 and 4; subspiracular lobe and surpedal lobe each with about 4 long setae; apical segment with about 12 long setae dorsally and with long setae on subanal area.

Prepupa: Differs from feeding stages by head, thorax, and abdomen entirely pale, whitish. Setae on head and body absent. Each mandible with 3 linear teeth; left mandible with outer tooth largest, basal 2 teeth smaller and subequal in size; right mandible with central tooth largest, outer and inner teeth smaller and subequal in size.

Type material. Takeuchi described this species from a single female "Sozan near Taihoku, Formosa" "collected by M. Kato, on May 2, 1926". The holotype should be in UOP with the Takeuchi collection. On a visit to Japan in 1979, I examined the holotype and took some brief notes. When recently requesting the type, it could not be found in the Takeuchi collection at UOP. A thorough search for the type was made by Noria Hirai (UOP) and Akihko Shinohara (National Museum of Nature and Science), but to no avail.

Formosempria annamensis was described from a single female. The holotype is at NHR, was examined and is labeled "Phuc Son, Annam, XI-XII, H Rosse, Berlin, s.w. 11", "TYPUS" [red], Formosempria annamensis n. sp., R. Malaise det 1958, "NHRSHEVA 000000839".

Formosempria metallica was described from nine female and male specimens from Hubei, Fujian, Zhejiang, Hangzhou provinces, China. The female holotype is at CSCS, from "Maheba, Xiangeng, Hubei, 1999-VII-25" and was examined. The holotype label is in Chinese, with the same date and " $450 \mathrm{~m}$." and additional labels "F. metallica", "Holotype: Formosempria metallica Wei female, M. Wei 1992".

Specimens examined. CHINA: Hong Kong, Sham Tseng San Tsuen Temple, larvae, March 24, 2013, on Paederia foetida, adults April 2013, reared in quarantine, ARS, Ft. Lauderdale, FL by Paul Pratt (5 $+5{ }^{\lambda}$, USNM); same data, larvae March 

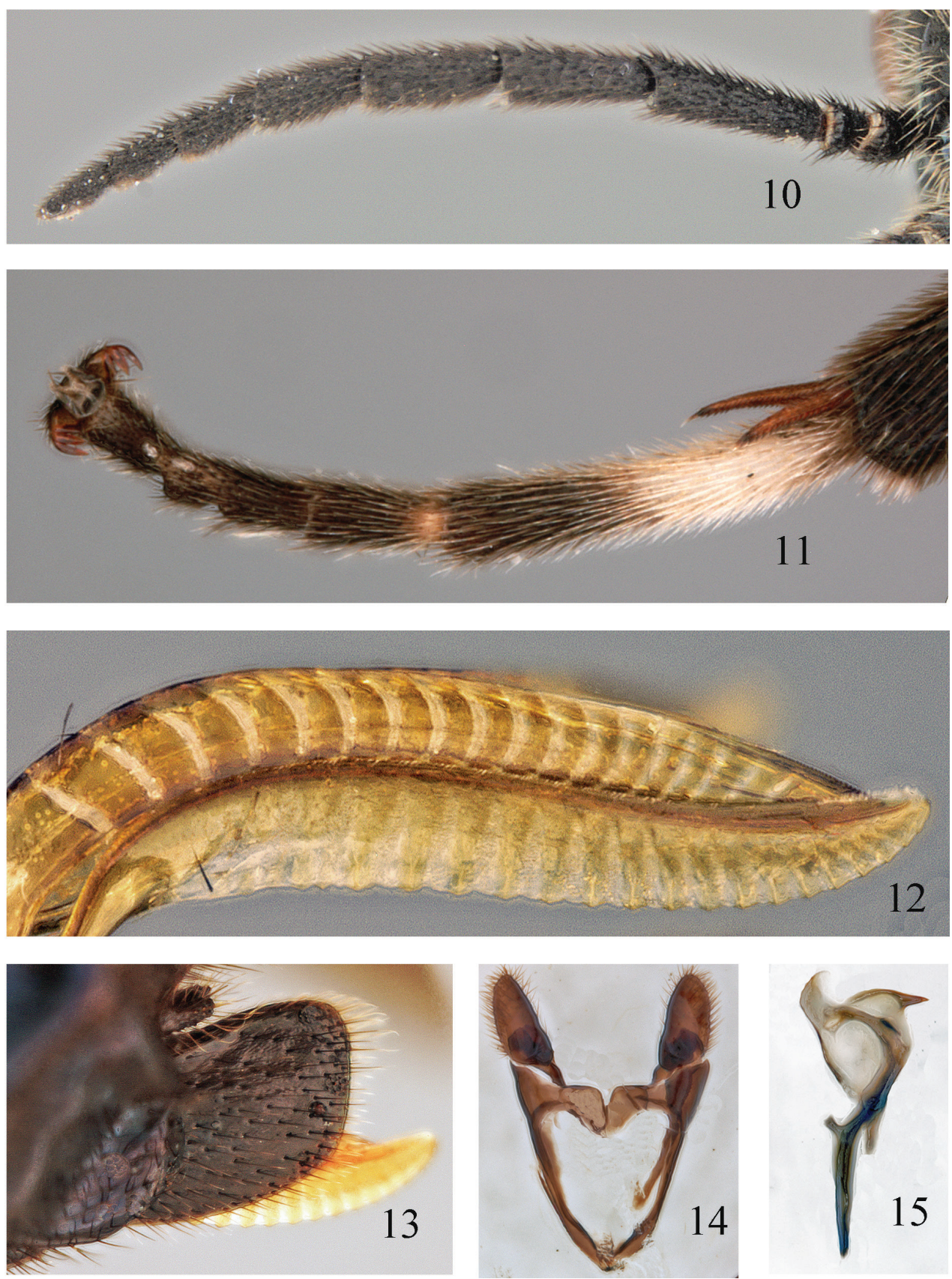

Figures 10-15. Formosempria varipes. 10 Antenna II Hind tarsus $\mathbf{2}$ Ovipositor $\mathbf{3}$ Female sheath, lateral I 4 Male genital capsule, ventral I 5 Male penis valve, lateral. 
2014, pupated and adults emerged IV-V 2014 (about 7 ㅇ, 100 $\overbrace{}^{\lambda}, 20$ larvae, USNM, IPRL); Hubei, holotype and paratype of $F$. metallica (1,$+ 1 \hat{\jmath}$, CSCS); Zhejiang, paratype; Henan (1 9 , SDEI). TAIWAN: Keelung Co., Keelung City, V.2004, Malaise trap, L. Stange and H. Wang (1 $q, 4 \delta$, FSCA). VIETNAM: Holotype of $F$. annamensis (1 9 , NHR).

Distribution. China (Hong Kong, Hubei, Fujian, Zhejiang, Hangzhou); Taiwan; Vietnam.

Hosts. Paederia foetida, also P. ciliata, P. cruddasiana, P. bojeriana, and P. pilifera based on host testing (Rubiaceae).

Comments. The interpretations of F. varipes by Malaise (1961), Togashi (1990) and others were based on the original description by Takeuchi (1929), not examination of the type. The type is now presumed lost. In a collection of sawflies from Taiwan (FSCA) DRS discovered a series of four males and one female that agree with Takeuchi's description. Due to the absence of the type, we are using these specimens as representative of $F$. varipes. A key character used by Malaise (1961) and others to separate $F$. varipes is the length of the hind basitarsomere. Takeuchi (1929) stated "posterior basitarsus shorter than the following joints". In the specimens examined, the hind basitarsomere is subequal to very slightly longer than the remaining tarsomeres combined. This is the only discrepancy between the Taiwan specimens we have and Takeuchi's (1929) description. However, because of the overwhelming similarity of the Taiwan specimens with Takeuchi's description, we do not believe "shorter", "subequal", or "slightly longer", alone are sufficient to justify a separate species. This could have been misinterpreted by the authors, or it could be slightly variable in the species. The female ovipositor and male genitalia of the Taiwan and Hong Kong specimens were compared and were identical.

Togashi (1990) briefly described one female from Taiwan "Shin Bao Shi, near Liu Kui, 3.V.1986, K. Baba leg." He stated that it agrees with Takeuchi's original description. He illustrated the dorsal view of the head (fig. 46), front inner tibial spur (fig. 47), tarsal claw (fig. 48), sheath (fig. 49), and lancet (fig. 50). The front inner tibial spur was illustrated and stated to be simple; however, in specimens we have examined there is a very slight subapical projection. Otherwise, Togashi's description and illustration agree with the specimens examined from Taiwan. Togashi's specimen was not examined.

Malaise's holotype of $F$. annamensis from Vietnam is identical to specimens from Taiwan and Hong Kong; therefore, we synonymize this species.

Wei (in Wei and Nie 2003) stated that F. metallica “...differs from its congeners in malar space absent, lateral furrows of postocellar area very weak and shallow, antenna as long as half the body length, and mesoscutellum black". Figures in Wei and Nie (2003) of the male genitalia, tarsal claw, sheath and part of the lancet do not noticeably differ from specimens from Taiwan and Hong Kong. All of the differing characters mentioned by Wei are shared with $F$. varipes, and, upon examination of the holotype, DRS observed no differences between this and $F$. varipes. Thus, $F$. metallica is synonymized. 

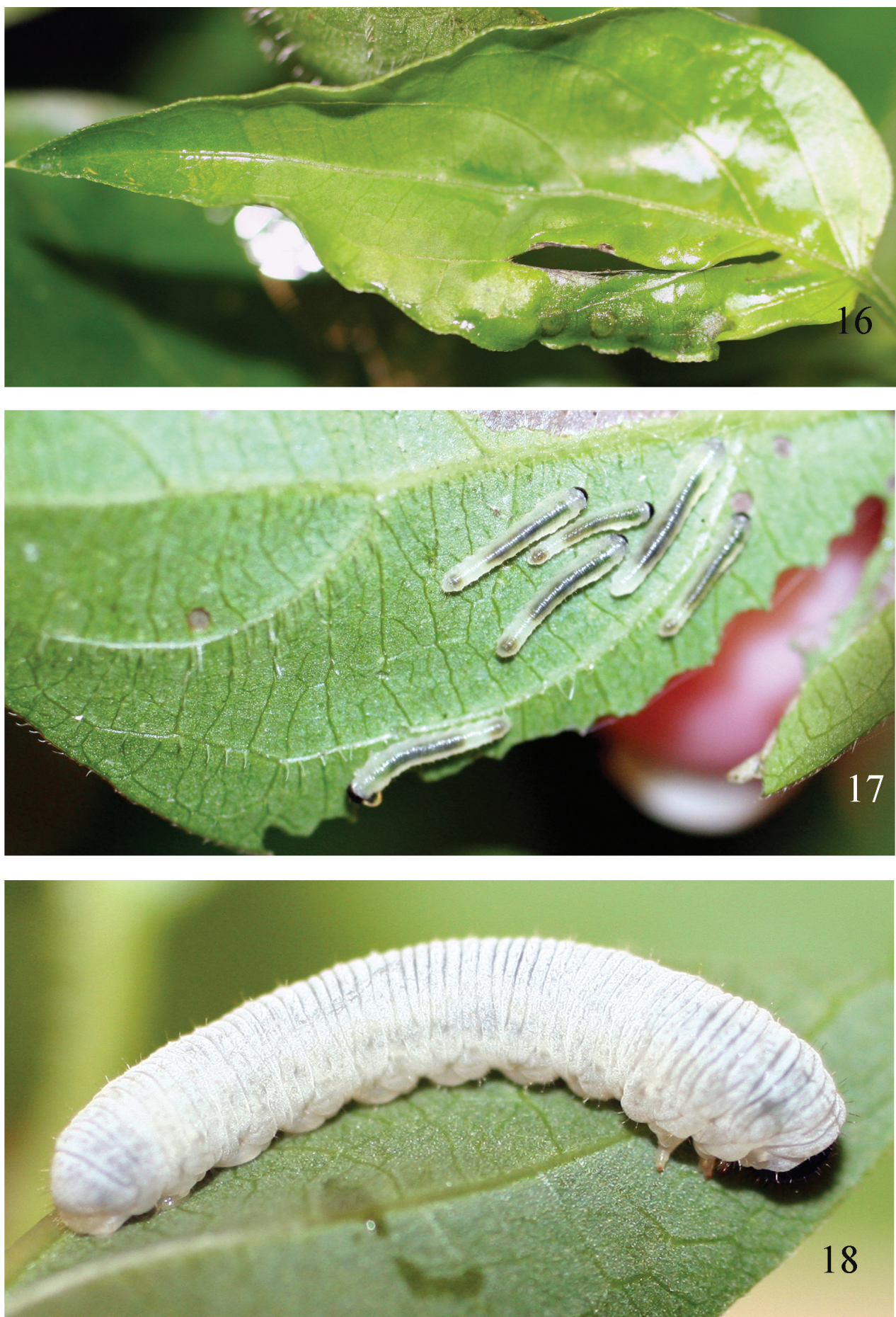

Figures 16-18. Formosempria varipes. 16 Eggs 17 Neonate larvae 18 Mature larva. 


\section{Biology and host specificity of Formosempria varipes}

The objective of importing F. varipes into the IPRL quarantine facility was to determine the sawfly's host range, from which inferences can be drawn concerning the herbivore's suitability as a biological control agent of $P$. foetida in Florida. Females from the 2013 survey were observed dragging their ovipositors across the leaf surface shortly after release into the cages, creating 1-2 cm longitudinal incisions through the leaf and typically located midway between the midvein and the leaf margin. Eggs (Fig. 16) were inserted between the adaxial and abaxil leaf surfaces, usually on the leaf margin but occasionally along the leaf midribs. Oviposition was consistently adjacent to the incision created by the female. The reason for this leaf cutting behavior is unknown but may be related to assessment of host plant suitability or the disruption of host plant defenses. In an effort to force mating, the heads of several males were excised and multiple attempts were made to mate females but all efforts were unsuccessful.

Neonates (Fig. 17) exited their leaf-enclosed eggs approximately one week following oviposition. Groups of first instar larvae were observed feeding gregariously, consuming the foliage between the leaf veins. First instar larvae were transferred to small, ventilated plastic cages and fed exclusively on $P$. foetida until pupation, demonstrating that the target weed is a developmental host. Later instars consumed entire leaves. Larvae (Fig. 18) possess a black head capsule but only later instars also have a fine wax covering the thorax and abdominal integument. The last instar larvae (prepupae) were observed wandering within the cages and lacked the wax covering, possessing instead a pale colored head capsule and integument. Prepupae were transferred to plastic boxes filled with a loose sandy soil, where the larvae readily burrowed below the surface. Pupation occurred within an oblong casing (cell) constructed, in part, from the surrounding soil. Adults emerged from their pupal cells approximately two weeks following pupation and tunneled to the surface of the soil. The subsequent $\left(\mathrm{F}_{1}\right)$ generation, however, were exclusively males and the laboratory colony was lost. These observations confirm that females of $F$. varipes are arrhenotokous.

A second collection of $F$. varipes larvae in Hong Kong was made in April 2014 and efforts to colonize the species were repeated. Adults arising from this 2014 shipment were also used in no-choice host range tests, which were designed to quantify the propensity of $F$. varipes to oviposit and feed on select Paederia species. Oviposition was observed among all replicates of $P$. ciliata and $P$. foetida tested. There was no difference in the number of larvae recovered from the Paederia species used in the ovipositional test $\left(\mathrm{F}_{1,9}=3.0 ; \mathrm{P} \leq 0.1214\right)$. From these data it is clear that $F$. varipes females readily oviposit on the Mexican endemic $P$. ciliata so no-choice larval feeding tests were conducted to determine if $P$. ciliata is also a developmental host. Survivorship varied among hosts $\left(\mathrm{F}_{4,24}=10.38 ; \mathrm{P}<0.001\right)$, with no individuals completing development when held with $P$. pilifera. Larval survivorship did not vary when feeding on the remaining species including $P$. foetida $(90.0 \%( \pm 0.05))$, P. cruddasiana $(88.0 \%( \pm 0.08))$, P. ciliata $(76.0 \%( \pm 0.10))$, or $P$. bojeriana $(52 \%( \pm 0.22))$. Host plant species also 
influenced development times $\left(\mathrm{F}_{3,17}=6.69 ; \mathrm{P}<0.005\right)$. Development from neonate to prepupa was shortest when feeding on $P$. foetida $(9.5$ days $( \pm 0.3))$ and $P$. bojeriana $(9.8$ $( \pm 0.5))$ but slowest when held with $P$. ciliata $(13.1( \pm 0.9))$, with $P$. cruddasiana $(11.6$ $( \pm 0.6))$ intermediate. Like those of 2013 , all efforts to establish a laboratory colony were unsuccessful with the 2014 material.

Although P. ciliata may not be an optimal host based on development rates, these data demonstrate that $F$. varipes will readily oviposit and complete development on the Mexican native under no-choice conditions. The risk $F$. varipes would pose to $P$. ciliata populations is a function of 1 ) host use, as reported herein, but also 2) the permeability of geographic barriers that inhibit landscape level dispersal of the herbivore from its intended range (Florida) to the native range of P. ciliata (central Mexico). While the dispersal pathway(s) remain unknown, there are several examples of biological control agents spreading far beyond their intended geographic ranges through natural or anthropogenic means (Pratt and Center 2012). Considering the ever increasing levels of tourism and trade between Florida and Mexico, the authors consider the probability of $F$. varipes dispersing to Mexico and threatening $P$. ciliata populations too great a risk to justify its release. Therefore, additional resources dedicated to the development of this species as a biological control agent are unwarranted.

\section{Acknowledgments}

We thank the following for loan of specimens: Hege Varrdal (NHR); Meicai Wei (CSCS); Stephan Blank (SDEI); and Jim Wiley (FSCA). We appreciate the help of Noria Hirai (UOP) and Akihiko Shinohara (National Museum of Nature and Science, Ibaraki, Japan), for attempting to locate the type of $F$. varipes. We thank Elizabeth Mattison, Angelica Moncada, Sophie Philizaire, and Tatum Norrell (IPRL, USDA) for rearing, testing, and curation. We also thank Bradley Brown (ABCL) for assistance with field searches and collections in Hong Kong. USDA is an equal opportunity provider and employer. Mention of trade names or commercial products in this publication is solely for the purpose of providing specific information and does not imply recommendation or endorsement by the USDA.

\section{References}

Abe M, Smith DR (1991) The genus-group names of Symphyta (Hymenoptera) and their type species. Esakia 31: 1-115.

Chou LY, Naito T (1991) Name lists of insects in Taiwan - Hymenoptera, Symphyta. Chinese Journal of Entomology 11: 85-95.

Haris A (2012) Sawflies from Vietnam (Hymenoptera: Symphyta). Natura Somogyiensis 22: $123-140$. 
Lacourt J (2003) Réflexions sur la classification des Blennocampinae, avec description d'un nouvelle espèce du sud de la France et de Corse (Hymenoptera, Tenthredinidae). Bulletin de la Société Entomologique de France 108: 49-529.

Malaise R (1961) New Oriental saw-flies (Hymen. Tenthr.). Entomologisk Tidskrift 82: 231-260.

Malaise R (1963) Hymenoptera Tenthredinoidea, subfamily Selandriinae, key to genera of the world. Entomologisk Tidskrift 84: 159-215.

Pemberton RW, Pratt PD (2002) Skunk vine (Paederia foetida). In: Van Driesche R, Blossey B, Hoddle M, Lyon S, Reardon R (Eds) Biological control of invasive plants in the eastern United States. US Forest Service, Morgantown, West Virginia, 343-351.

Pratt PD, Center TD (2012) Biocontrol without borders: the unintended spread of introduced weed biological control agents. BioControl 57: 31-329. doi: 10.1007/s10526-011-9412-4

Puff C (1991) Revision of the genus Paederia L. (Rubiaceae-Paederieae) in Asia. Opera Botanica Belgica 3: 207-289.

Saini MS (2006) Indian Sawflies Biodiversity, Keys, Catalogue and Illustrations (Vol. III), Subfamily Allantinae. Bishen Singh Mahendra Pal Singh, Dehra Dun, 205 pp.

Saini MS, Deep JS (1994) First record of Allantinae (Tenthredinidae: Hymenoptera: from India. Journal of the Bombay Natural History Society 91: 47-50.

Saini MS, Blank SM, Smith DR (2006) Checklist of the sawflies (Hymenoptera: Symphyta) of India. In: Blank SM, Schmidt S, Taeger A (Eds) Recent Sawfly Research: Synthesis and Prospects. Goecke \& Evers, Keltern, 575-612.

SAS (1999) The SAS system for windows, Version 8. SAS Institute Inc., Cary, North Carolina.

Taeger A, Blank SM, Liston A (2010) World catalog of Symphyta (Hymenoptera). Zootaxa 2580: 1-1064.

Takeuchi K (1929) New sawflies from Formosa (3). Transactions of the Natural History Society of Formosa 19: 83-91.

Togashi I (1990) Notes on Taiwanese Symphyta (Hymenoptera, Siricidae, Tenthredinidae, Argidae) (II). Esakia (Special Issue) 1: 177-192.

Wei M (2001) Symphyta. In: Wu H, Pan C (Eds) Insects of Tianmushan National Natural Reserve. Science Press, Beijing, 662-685. [In Chinese, English abstract]

Wei M, Nie H (1998) Generic list of Tenthredinoidea s. str. (Hymenoptera) in new systematic arrangement with synonyms and distribution data. Journal of Central South Forestry University 18: 23-31.

Wei M, Nie H (2002) Hymenoptera: Tenthredinidae. In: Huang F (Ed.) Forest Insects of Hainan. National Natural Science Foundation of China, 835-851.

Wei M, Nie H (2003) Blennocampidae. Hymenoptera. In: Huang B (Ed.) Fauna of Insects in Fujian Province of China, Vol. 7. Fujian Press of Science and Technology, Fuzhou, 127-162.

Wei M, Nie H, Taeger A (2006) Sawflies (Hymenoptera: Symphyta) of China - Checklist and review of research. In: Blank SM, Schmidt S, Taeger A (Eds) Recent Sawfly Research: Synthesis and Prospects. Goecke \& Evers, Keltern, 505-574.

Xiao G (2006) Suborder Chalastogastra (Symphyta). In: Hua L (Ed.) List of Chinese Insects, Vol. IV. Sun Yat-sen University Press, Guangzhou, 187-200. 